\title{
Gazoduc "Artère de Guyenne"
}

Nathalie Fourment et Pierre Régaldo

URL : http://journals.openedition.org/adlfi/7573

ISSN : 2114-0502

Éditeur

Ministère de la culture

\section{Référence électronique}

Nathalie Fourment et Pierre Régaldo, "Gazoduc "Artère de Guyenne" », ADLFI. Archéologie de la France Informations [En ligne], Aquitaine, mis en ligne le 01 mars 2007, consulté le 20 avril 2019. URL : http:// journals.openedition.org/adlfi/7573

Ce document a été généré automatiquement le 20 avril 2019.

(c) Ministère de la Culture et de la Communication, CNRS 


\title{
Gazoduc "Artère de Guyenne"
}

\author{
Nathalie Fourment et Pierre Régaldo
}

Identifiant de l'opération archéologique : 025047

Date de l'opération : 2007 (EX)

1 Le renforcement de « l'artère de Guyenne » par la construction d'un nouveau gazoduc a occasionné des reconnaissances archéologiques selon une procédure adaptée.

2 Dans un premier temps, une étude documentaire a été réalisée par Sandra Malpelat, dans le cadre d'un stage de Master de l'université de Lyon II. Puis, hors d'un cadre préventif strict, le maître d'ouvrage a commandé à l'Inrap une prospection pédestre du tracé dont Jacques Pons a été chargé (BSR 2006, p. 101).

3 Ces démarches ont permis de définir des segments de forte sensibilité où un diagnostic devait être réalisé, au total un peu plus de $20 \mathrm{~km}$. Sur l'essentiel de ces zones prioritaires, furent menées des tranchées exploratoires avec des phasages tenant compte des différences d'occupation des terrains; les secteurs du Bazadais et de la vallée de la Garonne furent confiés à Jacques Pons ; l'Entre-deux-Mers, de Blasimon à Mouliets-etVillemartin, à Marie-Christine Gineste. Le site de Lacoste, qui ne pouvait être évité par les travaux, fut traité différemment : un décapage de la moitié de l'emprise et des sondages ponctuels, Isabelle Kerouanton a assumé cette opération.

4 Sauf sur ce dernier site, le diagnostic a permis de traiter les découvertes archéologiques. En Gironde, l'apport de l'opération, sous réserve de l'achèvement des synthèses en cours, devrait être non négligeable en termes de connaissance de l'occupation ancienne au long de ce transect sud-nord.

5 En Dordogne, pour des raisons propres aux difficultés rencontrées par l'Inrap dans la programmation des diagnostics et leur mise en place effective, aucune opération de terrain n'a été réalisée. Les dispositions de l'article 30 du décret 2004-490 portant fixation des délais de réalisation des opérations de diagnostic ont dû être appliquées, alors même que le projet avait fait l'objet d'une anticipation et d'une compréhension réelles de la part du maître d'ouvrage, GRT Gaz. 
Régaldo Pierre (Sra), Fourment Nathalie (Sra)

INDEX

Thèmes : aqueduc, documentation

Index géographique : Aquitaine, Gironde (33), Captieux, Laprade operation Expertise (EX)

\section{AUTEURS}

NATHALIE FOURMENT

SRA

PIERRE RÉGALDO

SRA 